\title{
Disease and risks associated with contact lenses
}

Contact lens (CL) wear, as an alternative to spectacles for the treatment of low refractive errors, is widespread in developed countries. It results in a number of inevitable ocular changes which, with the exception of endothelial polymegethism, are short term and recover after lens wear has ceased; these effects are seldom of functional significance.

The risks of lens wear result from both these inevitable ocular responses and the additional potential that exists for developing a $\mathrm{CL}$ associated disease. These risks must be set against the optical and cosmetic advantages and convenience resulting from lens use. This risk:benefit ratio should be considered by all contact lens users and practitioners before embarking on lens wear.

Contact lens associated disease, as opposed to the inevitable consequences of wear, develops in only some contact lens users. It includes minor ocular adverse reactions such as corneal neovascularisation, representing a suboptimal ocular response to the stress of lens wear, as well as severe complications such as microbial keratitis.

This review summarises the effect of these on the community, the features distinguishing CL related disorders from other external eye diseases, their classification, and epidemiology.

\section{The consequences of lens related disease for primary eye care}

Estimates of the prevalence of lens wear are based on market research and not widely available or precise but they indicate that there are approximately 1.65 million CL users in the adult population of the United Kingdom. ${ }^{1}$ In pooled United States Food and Drug Administration premarket approval studies the incidence of severe, sight threatening, adverse reactions has been from 1:244 per year $(n=3907)$ in gas permeable hard CL use to 1:70 per year $(n=1276)$ in extended wear soft $\mathrm{CL}$ use. ${ }^{2}$ Minor complications have been reported in $20 \%(n=100)$ of daily soft contact lens users over a 3 year follow up period, ${ }^{3}$ and individual minor complications, such as red eye reactions, in $27 \cdot 5 \%(n=400)$ of patients using extended wear soft lenses from $0-4$ years. ${ }^{4}$ This represents a large potential primary eye care problem for the population.

Although most problems are treated by private contact lens practitioners some are complex or serious and others difficult to diagnose and manage. This results in substantial and increasing demands on resources in both the accident and emergency departments and eye clinics of our public hospitals; studies at the same accident and emergency department in London have shown that lens related problems accounted for $2 \cdot 6 \%$ of all new patients in $1978^{5}$ rising to $3 \cdot 8 \%$ $(1104 / 29242)$ in $1988 .^{6}$ This proportion will vary depending on the penetrance of CL use in the catchment population of the hospital and has been as high as $10 \%$ in a study in another part of London. ${ }^{7}$ Similar figures have been reported from the United States. ${ }^{8}$

These services are often ill equipped to respond to the problems of contact lens related disease. These include both a substantial group of newly described disorders and different manifestations of established external eye diseases. This has not yet been recognised in either general textbooks of ophthalmology or textbooks on corneal and external diseases with many disorders described only in the CL literature. In addition, further conditions are continually being described as the ocular tissues respond to challenge by new lens materials, lens care regimes, and wearing patterns. As a result the effective management of $\mathrm{CL}$ related disease requires specialist knowledge within the corneal and external disease services provided by ophthalmic units. The diagnosis and management of sight threatening CL related disease, however, is within the province of all ophthalmologists providing general services.

\section{The ocular response to contact lens wear}

Contact lenses have a wide range of predictable effects on the eye including the tear turnover, ${ }^{10}$ oxygen availability, corneal metabolism, epithelial and endothelial morphology, and sensation. " The conjunctiva may also be affected by hypoaesthesia, ${ }^{12}$ depletion of oxygen, ${ }^{13}$ and altered epithelial morphology. ${ }^{14}$ With the exception of corneal endothelial polymegethism all these changes are reversible soon after discontinuing lens wear. Polymegethism is probably related to chronic corneal stromal acidosis resulting from lens wear and occurs with all current types of lenses with the possible exception of silicone rubber. ${ }^{11}$ It is probably not fully reversible and in some cases may be associated with endothelial cell loss. ${ }^{15}$ Functional consequences can be measured ${ }^{16}$ and significant disease may rarely result. ${ }^{17}$

\section{Contact lens related diseases}

These anticipated short and long term effects of the CL on the eye result from the effect of the lens as a biomaterial. In common with other biomaterials, such as intraocular lenses and hip prostheses, the three principal effects on tissues in contact with the biomaterial are physiological, anatomical, and the consequences of introducing a biologically active surface. Contact lens related disease can be understood in these terms and some of the better characterised CL related diseases illustrate this concept.

Corneal neovascularisation is principally a physiological effect resulting from reduced corneal oxygen availability, due to the relatively low oxygen transmission of some contact lenses. This is most often seen at the upper limbus, in soft contact lens wearers, where the cornea is already exposed to reduced oxygen tension levels, because of upper lid cover. These levels are further reduced by the presence of a lens."

A type of corneal dellen, 3 and 9 o'clock keratopathy (peripheral stain), ${ }^{18}$ is an anatomical effect resulting from interference by a hard CL with tear resurfacing by the lid. This is probably due to a combination both of physical separation of the lid from the corneal limbus by the lens edge, and from the inhibitory effect of the lens on the blink reflex. ${ }^{1819}$

Contact lens associated papillary conjunctivitis (giant papillary conjunctivitis) is the result of the CL developing a biologically active surface in which there is an allergic response to ocular deposits that have accumulated on the lens surface. In common with other biomaterials the lens surface rapidly 
becomes coated with materials derived from its environment including bacteria, cell debris, mucus, and proteins. ${ }^{20}$

Many lens related disorders may be the result of complex interactions in which two or more of these effects are combined in the pathogenesis. An example is bacterial keratitis. Important factors are the increased susceptibility of the CL wearing eye to bacterial infection resulting both from epithelial trauma and/or physiological stress, particularly in extended wear, ${ }^{21223}$ the exposure of the eye to pathogenic bacteria contaminating the lens case $\mathrm{e}^{24} 25$ and adhering to the lens, ${ }^{262728}$ or directly colonising the lens surface ${ }^{29303132}$ and reduced clearance of organisms from the ocular surface due to interference with tear flow and tear resurfacing by the lids. $^{33}$

\section{Classification of lens related disease}

Our current understanding of the pathogenesis of CL related disease is adequate for a clinical classification based on the adverse ocular effects of CL wear. This approach to the classification of CL related disorders assists in understanding both their development and management unlike the commonly used anatomical classifications. The clinical classification of disease described here was developed for clinical research projects ${ }^{67}$ and is based on both the concept of the CL as a biomaterial and the probable pathogenesis. Twenty of the more common CL related diseases, their clinical characteristics, and probable pathogenesis are summarised in Table 1.

The risks of lens related disease

There has been some recent interest in the use of formal epidemiological studies to provide more information about some aspects of CL related disease. These studies have aimed both to assess the effect of some contact lens related diseases on the population as a whole, to establish if the incidence and/ or risk of some complications was greater for some types of contact lens and patterns of wear than others, and to assess potential causes with multivariable analysis of associated factors.

\section{MICROBIAL KERATITIS}

The impetus for these studies has been principally related to widespread concern about CL wear as a predisposing factor for microbial keratitis, the major sight threatening complication of CL use, and in which bacteria, particularly Pseudomonas, have been the major cause. ${ }^{31} 50$ s1 Attention was drawn to this problem by the publication of simple descriptive studies and keratitis case series. In these the number of CL users suffering from keratitis were seen to be overrepresented, as were extended wear soft contact lenses in comparison to other lens types. ${ }^{50} 52$ The studies carried out for licensing in the United States before the introduction of new lenses there, as well as post marketing studies of CL users, were uncontrolled, often small, and carried out on carefully selected users. ${ }^{2}$ As a result these did not predict the problems that have become apparent now that these lenses have increased in popularity and are being used by millions of young adults. The principal findings of the recent case control ${ }^{5354}$ and incidence studies ${ }^{55}$ can be reasonably extrapolated to all countries where contact lenses have a major share of the optical appliance market. The case control study of microbial keratitis in the United Kingdom has shown that CLs are now the major associated cause of microbial keratitis in London with a risk that is significantly higher than that for corneal trauma. ${ }^{54}$ The relative risk (RR) with $95 \%$ confidence limits (given in brackets) of keratitis associated with these causes, compared with cases without an identifiable predisposing factor (the referent with a baseline risk of 1.0 ) was 80 times (38-166) higher for CL wear and 14 times (6-32) for trauma. Contact lens wear, principally of soft CLs, was also shown to be responsible for $65 \%$ of all new microbial keratitis cases at this centre where no serious cases attributable to this cause had been reported a decade earlier. This study also showed that, compared to hard CLs, the risk for extended wear soft CLs was 21 times (7-60) and daily wear soft CLs 3.6 times (1-14). Continuous periods of extended wear of more than 6 days were associated with a further increase in the risk of keratitis. This study confirmed the results both of a previous pilot study carried out in London ${ }^{7}$ and of an independent case control study of ulcerative keratitis, carried out in multiple centres in the United States, which showed that the risk of extended wear soft CL use was 9-15 times higher than that for daily wear soft CLs and that the risk was incrementally related to the period of extended wear; the RRs for hard CLs could not be assessed..$^{53}$ An incidence study in New England, carried out at the same time as this case control study estimated an annual incidence for ulcerative keratitis in the United States of 20.9:10000 (15.1-26.7), for extended wear soft CL use compared to $4 \cdot 1: 10000(2 \cdot 9-5 \cdot 2)$, for daily wear soft CLs. Applying these incidence figures to estimates of the size of the CL using population in the United States gave an estimated incidence of 12000 new cases per year in the soft CL using population. Extrapolation of these incidence data to the relative risks shown in the United Kingdom study for gas permeable hard CLs gives an estimate of the annual incidence of 1:10000 for this lens type. Similar application of these incidence estimates to the data in the London study using the figure of 1.65 million for the estimated population of $\mathrm{CL}$ users in the United Kingdom gives a rough annual estimate of 840 new cases of CL related microbial keratitis per year. Although the incidence of soft CL wear associated keratitis defined in the New England study is the most precise currently available one large retrospective survey of contact lens practitioners, including 196000 daily wear soft lens users and 72100 extended wear lens users, in the United States produced estimates as high as 350:10000 for extended wear soft CLs and 50:10000 for daily wear soft CLs; at the upper level of the confidence limits in the New England study. ${ }^{56}$

\section{ACANTHAMOEBA KERATITIS}

Acanthamoeba keratitis is a rare, painful, and disabling cause of keratitis ${ }^{57}$ which may also result in scleritis ${ }^{58}$ and chorioretinitis. ${ }^{59}$ Contact lens wear is associated in $85 \%$ of cases but no differences in risk have yet been identified for the different types of lens, ${ }^{60}$ although a recent case series has disposable soft lens wear as a risk factor in the United Kingdom. ${ }^{6}{ }^{6}$ The use of home made saline solutions has been identified as a risk factor in the United States. ${ }^{62}$ The prognosis is good following early diagnosis and the use of effective medical therapy. ${ }^{636}$ However treatment is often delayed because of misdiagnosis, usually as herpes simplex virus or fungal keratitis ${ }^{65}$ Currently this disease is apparently increasing in frequency in the United Kingdom ${ }^{61}$ and familiarity with the early signs of disease, punctate keratopathy, pseudodendrites, epithelia infiltrates, diffuse or focal subepithelial infiltrates, ${ }^{66}$ and radial keratoneuritis ${ }^{67}$ is important to reduce the morbidity. The ring infiltrate and corneal ulceration are usually late signs of disease. ${ }^{68}$ Acanthamoeba must be considered in the differential diagnosis of contact lens users with an atypical keratitis in whom the diagnosis of herpes keratitis should be treated with scepticism.

\section{OTHER COMPLICATIONS}

The risks of other adverse responses of CL wear have been 


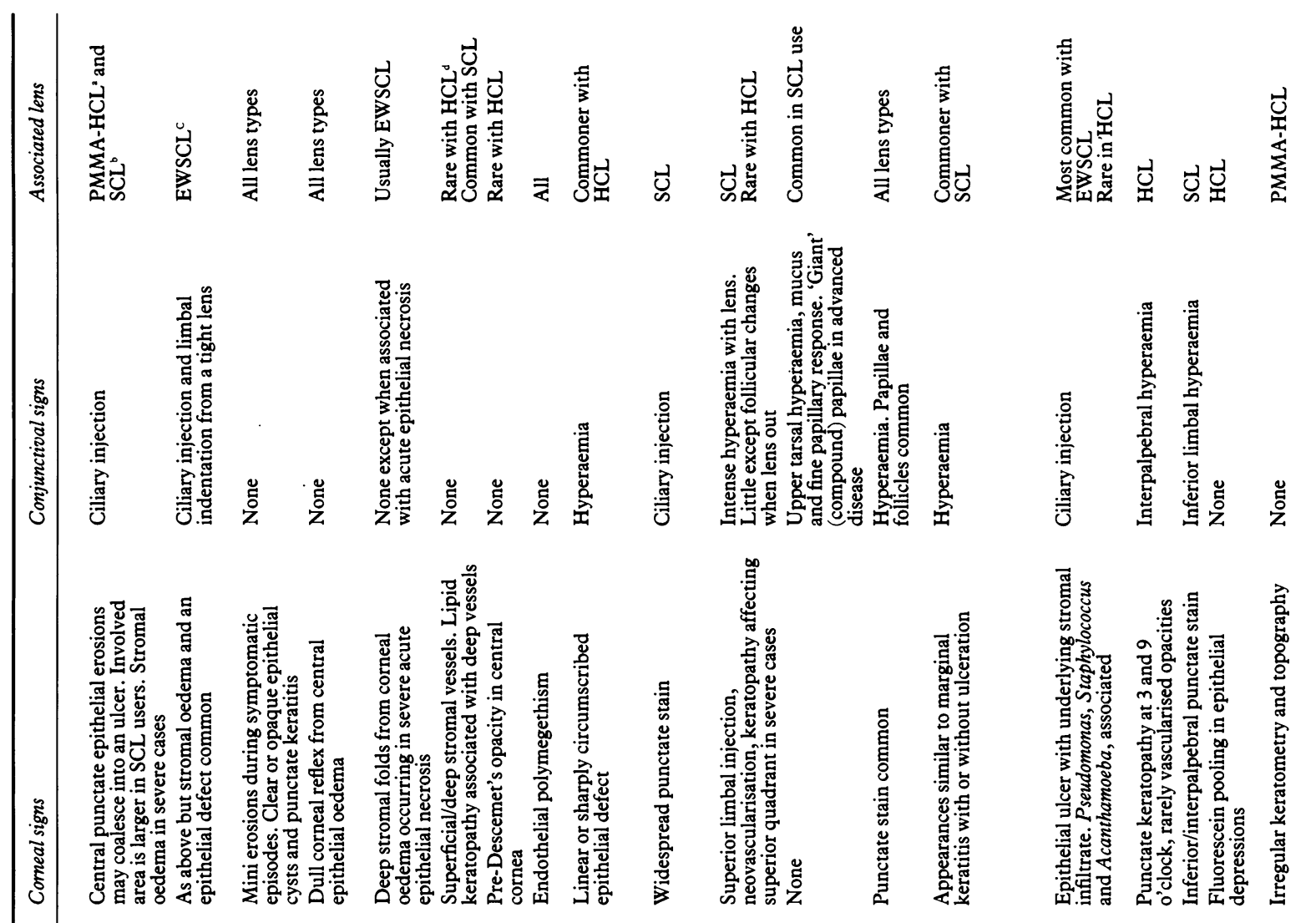

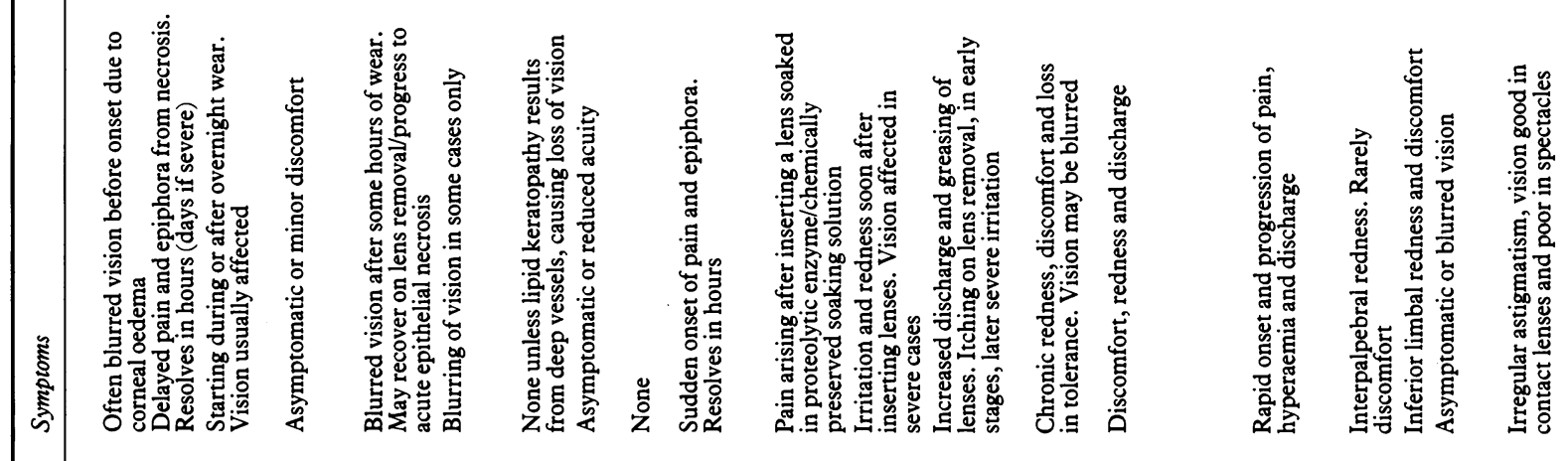

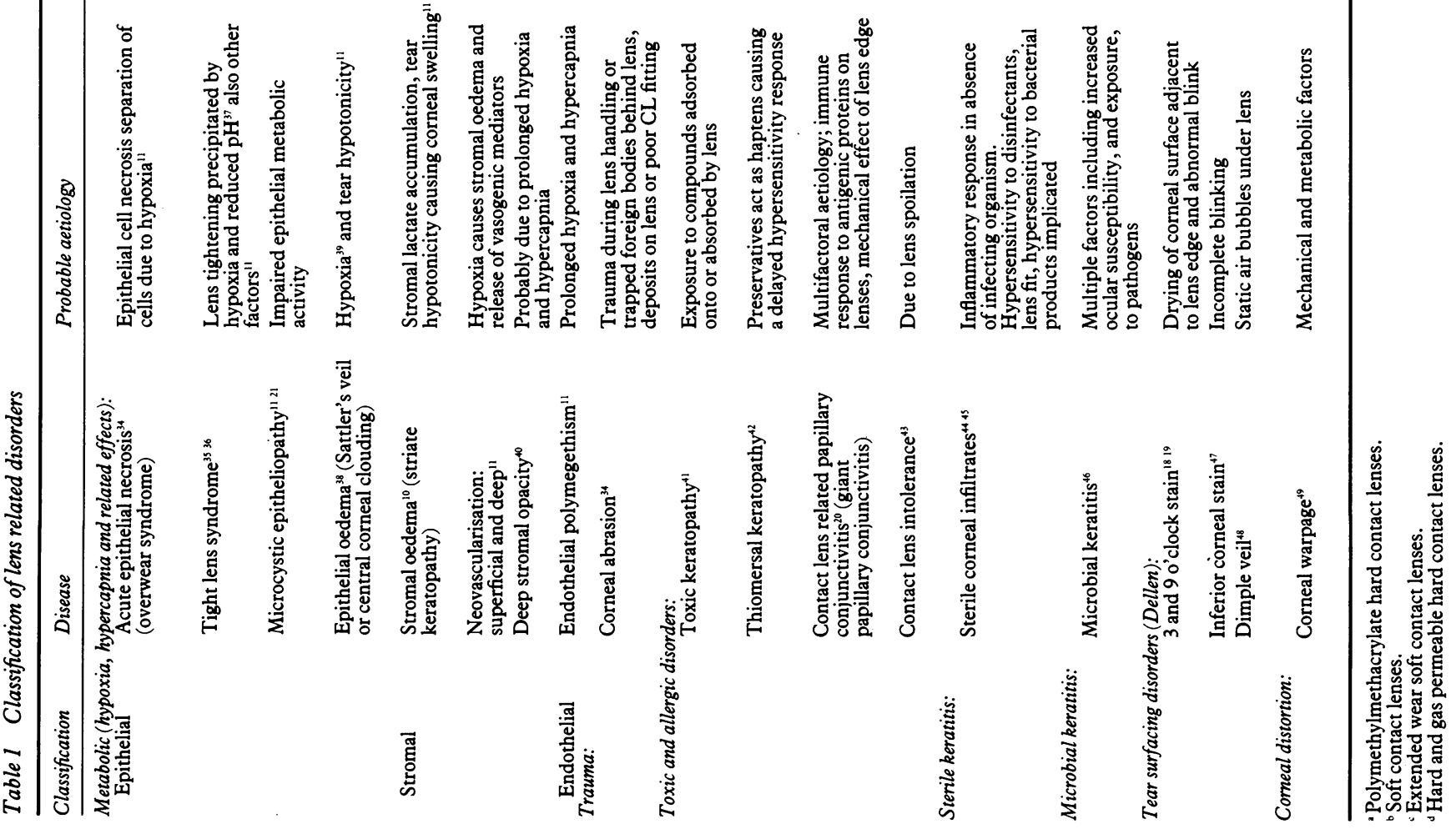


assessed in small uncontrolled studies and in some larger retrospective studies. Overall risks of lens related disease for hard contact lenses have been infrequently reported. Analysis of the pooled results of 48 consecutive premarketing studies on 22739 CL users for the Food and Drug Administration in the United States have given annualised incidence rates for severe adverse reactions (including keratitis, uveitis, abrasion, infiltrate, oedema, vascularisation, and scarring) of $1: 244(41: 10000)$ in gas permeable daily CL wear, 1:189 (53:10 000) for daily wear soft CL wear, and 1:70 (143:10000) for reusable extended wear soft CL wear. ${ }^{2}$ These studies are carried out carefully but uncontrolled and on volunteer users. For these reasons they may not represent the real postmarketing situation. A large retrospective Japanese study on $66218 \mathrm{CL}$ users gave annualised incidence rates for a variety of ill defined adverse reactions as $16: 1000$ (160:10000) for polymethylmethacrylate hard CLs, 6:1000 (60:10000) for gas permeable hard CLs, and 12:1000 (120:10000) for low water content soft CLs. ${ }^{69}$ Other smaller prospective and retrospective uncontrolled studies have been carried out in daily wear soft CL use giving incidences of all adverse reactions of $20 \%(n=100$ followed for 3 years an annualised incidence of $6 \cdot 3 \%[630: 10000]){ }^{3}$ For extended wear soft lenses studies are available from which annualised incidence rates can be calculated. These range around $1.81 \%$ $(181: 10000[n=1099])^{70}$ for serious complications. Other studies with useful data on the rate of CL complications do not permit the calculation of annualised incidence rates from the data presented. ${ }^{471} 72$ These data are difficult to interpret in a way which allows meaningful comparison of the risks associated with the wear of different lens types. Because of this, case control studies have been used to estimate the risks for the development of acute and subacute complications of lens wear. Compared to gas permeable hard contact lenses (the referent with a baseline risk of $1 \cdot 0$ ), extended wear soft lenses had the largest overall risk for any complication at $2 \cdot 7$ times $(1 \cdot 73-4 \cdot 16)$ followed by daily wear soft CLs at $1 \cdot 3$ times $(1 \cdot 0-1 \cdot 72)$. The greatest differences in risk were for metabolic disorders [2.1 times $(1 \cdot 28-3 \cdot 4)]$ and sterile infiltrates [2.4 times $(1 \cdot 22-4 \cdot 84)]$ in extended wear soft CL use and for toxic/ allergic disorders [5.9 times $(3 \cdot 27-10 \cdot 49)]$ in daily wear soft $\mathrm{CL}$ use. Corneal abrasion was the only complication to occur more often in gas permeable hard CL use at 2.9 times more compared to daily wear soft CL use [0.34 times $(0 \cdot 24-0 \cdot 47)]$ and 4.4 times more compared to extended wear soft CL use $[0 \cdot 226(0 \cdot 13-0 \cdot 40)] .{ }^{6}$ These results confirmed the findings of previous pilot studies on complications ${ }^{7}$ and sterile corneal infiltrates. $^{44}$

\section{Disposable contact lenses}

Disposable soft contact lenses have only become widely available in the last 4 years and experience with these is limited. Enthusiasm for this type of lens wear is based on the theoretical advantages due to the potential for elimination of problems relating to surface deposits, in particular contact lens associated papillary conjunctivitis, and solution reactions. ${ }^{73}$ The potential reduction of other complications, in particular microbial keratitis, was less certain and metabolic complications would be expected to be identical. ${ }^{174}$ Several studies have reported a low incidence of adverse reactions. ${ }^{75677}$ However these study designs are unlikely to identify less common but serious disorders, such as keratitis, for which a relatively low incidence only becomes important when there is a large population at risk. Case series and reports have shown that keratitis may occur in disposable CL wear. ${ }^{74}$ A case control study design is ideally suited to investigating whether there are differences in risks between lens types, allowing comparison of new types of lens and lens wearing regime with those for which the level of risk is better established. ${ }^{6}$ Small case control studies using this methodology suggest that risks for both sterile and microbial keratitis may be as great or greater than those for conventional soft lens wear ${ }^{78} 79$; failure of compliance with recommended lens care and wear regimes may be one cause of this. It is to be hoped that disposable lenses will deliver the reduced risks of allergic and toxic adverse reactions that was expected and apparent in pilot studies. This may not be the case. ${ }^{80}$ Although the disposable concept has potentially much to offer in terms of safety and convenience these lenses should be treated with the same caution as other types of lens for the present.

\section{The prevention and management of contact lens related disease}

That contact lenses have optical, occupational, sporting, and cosmetic advantages for millions of individuals is clear. However the individual lens user who develops a serious complication is often surprised to discover that risks are attached to their use. Also the size of this population now at risk, of even infrequent serious adverse reactions, has resulted in an increasing problem for those delivering primary eye care. This situation has arisen because of the success of contact lenses as a form of optical correction. Emphasis on their convenience and, for extended wear and disposable lenses, their carefree aspects has led to their widespread introduction and the tendency to trivialise their use. ${ }^{81}$ The clear demonstration of differences in risk for different lens types, and the increased risks associated with the use of extended wear, should be understood by all contact lens practitioners in the context both of the population of contact lens wearers and their own practice. The contact lens user must also be educated about the risks of lens wear, and the importance of compliance with the appropriate hygiene and lens wear regimes, so that an informed choice can be made; this is now a complicated area which should not be the province of the inadequately trained. A better understanding of the nature of adverse reactions is needed to provide safer contact lens wear.

When adverse reactions do occur their morbidity can be limited if the problem is rapidly identified and appropriately managed. This is particularly important for keratitis which the general ophthalmologist in the United Kingdom must be competent to deal with. The remaining adverse reactions are usually self limiting if lens wear is discontinued. Referral to a contact lens practitioner who is competent to deal with this specialised area of external and corneal disease is then required. An increased level of education, for both ophthalmologists and contact lens practitioners, is needed to deal more effectively with this problem.

Moorfields Eye Hospital,

JOHN K G DART

City Road

London EC1V 2PD

I wish to thank Ms Alison Mathews FBCO and Dr Fiona Stapleton, PhD, for their assistance in the preparation and review of the manuscript.

1 Disposable contact lenses. [Editorial.] Lancet 1988; i: 1437.

2 MacRae S, Herman C, Stulting RD, Lippman R, Whipple D, Cohen E, et al. Corneal ulcer and adverse reaction rates in premarket contact lens studies. Am F Ophthalmol 1991; 111: 457-65.

3 Nilsson SE, Lindh H. Daily contact lens wear; a three year follow up. Acta Ophthalmol (Kbh) 1984; 62: 556-65.

4 Lamer L. Extended wear contact lenses for myopes; a follow-up study of 400 cases. Ophthalmology 1983; 90: 156-61.

5 Barry PJ, Ruben M. Contact lens injuries; an analysis of 217 consecutive patients presenting to Moorfields Casualty Department. Contact Lens $\mathcal{f} 1980$ 9: 6-10.

6 Stapleton F, Dart J, Minassian D. Non-ulcerative complications of contact len wear; relative risks for different lens types. Arch Ophthalmol 1992, in press.

7 Franks WA, Adams CGW, Dart JKG, Minassian D. Contact lens related disease in an ophthalmic casualty department and the increased risk of soft contact lens wear. $B M \mathcal{F}$ 1988; 297: 524-5.

8 Genvert GI, Cohen EJ, Parlato CJ, Donnenfeld ED, Jeffers JB. A prospective study of emergency room visits for contact lens related problems. CLAOF 1987 ; $13: 42-5$. 
9 Sorensen T, Taagelis F, Christiansen V. Tear flow and soft contact lenses. Acta Ophthalmol (Kbh) 1980; 58: 182-7.

10 Cedarstaff TH, Tomlinson A. A comparative study of tear evaporation rates and water content of soft lenses. Am f Optom Physiol Opt 1983; 60: 167-74.

11 Bruce AS, Brennan NA. Corneal pathophysiology with contact lens wear. Surv Ophthalmol 1990; 35: 25-58.

12 Norn MS. Conjunctival sensitivity in pathological cases with simultaneous measurement of corneal and lid margin sensitivity. Acta Ophthalmol (Kbh) 1975; 53: 450-7.

13 Hill RM, Fatt I. Oxygen depletion of a limited reservoir by human conjunctiva. Nature 1963; 200: 1011-2.

14 Price MJ, Morgan JF, Willis WE, Wilson G. Tarsal conjunctival appearance in contact lens wearers. Contact Intraocular Lens Med F 1982; 8: 16-22.

15 MacRae SM, Matsuda M, Shellans S, Rich LF. The effects of hard and soft contact lenses on the corneal endothelium. Am $f$ Ophthalmol 1986; 102: 50-7. 16 Polse KA, Brand RJ, Cohen SR, Guillon M. Hypoxic effects on corneal morphology and function. Invest Ophthalmol Vis Sci 1990; 31: 1542-54.

17 Rao GN, Aquavella JV, Goldberg SH, Berk SL. Pseudophakic bullous keratopathy. Relationship to preoperative corneal endothelial status. Ophthalmology 1984; 91 : $1135-40$.

18 Mackie IA. Localised corneal drying in association with dellen, pterygia and related lesions. Trans Ophthalmol Soc UK 1971; 91: 129-45.

19 Kline L, DeLuca T, Fishberg G. Corneal staining relating to contact lens wear. f Am Optom Ass 1979; 50: 353-7.

20 Allansmith MR, Abelson MB. Ocular allergies. In: Smolin G, Thoft RA, eds. The comea; scientific foundations and clinical practice. Boston: Little, Brown, 1983; Chap 6:240-1.

21 Holden BA, Sweeney DF, Vannas A, Nilsson KT, Efron N. Effects of longterm extended contact lens wear on the human cornea. Invest Ophthalmol Vis Sci 1985; 26: 1489-501.

22 Mondino BJ, Weissman BA, Farb MD, Petit TH. Corneal ulcers associated with daily and extended wear contact lenses. Am $\mathcal{F}$ Ophthalmol 1986; 102: $58-65$

23 Lawin-Brussel CA, Refojo MF, Leong FL, Hanniuen L, Kenyon KR. Time course of experimental Pseudomonas keratitis in contact lens overwear. Arch Ophthalmol 1990; 108: 1012-9.

24 Mayo MS, Cook WL, Schlitzer RL, Ward MA, Wilson LA, Ahearn DG. Antibiograms, serotypes, and plasmid profiles of Pseudomonas aeruginosa associated with corneal ulcers and contact lens wear. $\mathcal{f}$ Clin Microbiol 1986; 24: $372-6$.

25 Larkin DFP, Kilvington S, Easty DL. Contamination of contact lens storage cases by Acanthamoeba and bacteria. Br f Ophthalmol 1990; 74: 133-5.

26 Dart JKG, Badenoch PR. Bacterial adherence to contact lenses. $C L A O \mathscr{f} 1986$; 12: $220-4$.

27 Butrus S, Klotz SA, Misra RP. The adherence of Pseudomonas aeruginosa to soft contact lenses. Ophthalmology 1987; 94: 1311-4.

28 Miller MJ, Wilson LA, Ahearn DG. Effects of protein, mucin and human tears on adherence of Pseudomonas aeruginosa to hydrophilic contact lenses. on adherence of Pseudomonas

29 Slusher MM, Myrvik QN, Lewis JC, Gristina AG. Extended-wear lenses, biofilm, and bacterial adhesion. Arch Ophthalmol 1987; 105: 110-5.

30 Dart JKG, Peacock LJ, Grierson I, Seal DV. Ocular surface, contact lens and bacterial interactions in a rabbit model. Trans Br Contact Lens Ass Conf 1988: 95-7.

31 Dart JKG. Predisposing factors in microbial keratitis: the significance of contact lens wear. Brf Ophthalmol 1988; 72: 926-30.

32 John T, Refojo MF, Hanninen L, Leong FL, Medina A, Kenyon KR. Adherence of viable and nonviable bacteria to soft contact lenses. Cornea 1989; 8: 21-33.

33 DiGaetano M, Stern GA, Zam ZS. The pathogenesis of contact lens-associated Pseudomonas aeruginosa corneal ulceration: II. An animal model. Comea 1986; 5: 155-8.

34 Lansche RK, Lee RC. Acute complications from present day corneal contact lenses; a report of 14 new cases. Arch Ophthalmol 1960; 64: 275-85.

35 Stark WJ, Kracher GP, Cowan CL, Taylor HR, Hirst LW, Oyakawa RT, et al. Extended-wear contact lenses and intraocular lenses for aphakic correction. Am f Ophthalmol 1979; 88: 535-42.

36 Netland PA. Tight lens syndrome with extended wear contact lenses. CLAOF 1990; 16: 308.

37 Stark WJ, Kracher G, Martin NF. Extended-wear soft contact lenses for aphakia and myopia. In: Koch DD, Parke II DW, Paton D, eds. Current management in ophthalmology. New York: Churchill Livingstone, 1983: 87-115.

38 Dallos J. Sattler's veil. Brf Ophthalmol 1946; 30: 607-13.

39 Mandell RB, Polse KA. Corneal thickness changes accompanying central ocular clouding. Am f Optom Physiol Opt 1971; 48: 129-32.

40 Remeijer L, van Rij G, Beekhuis WH, Polak BCP, van Nes J. Deep corneal stromal opacities in long-term contact lens wear. Ophthalmology 1990; 97: 281-5. 41 Morgan J. Complications associated with contact lens solutions. Ophthalmology

42 Wilson-Holt N, Dart JKG. Thiomersal keratoconjunctivitis, frequency, clinical spectrum and diagnosis. Eye 1989; 3: 581-7.

43 Tripathi RC, Tripathi BJ, Millard CB. Physicochemical changes in contact lenses and their interactions with the cornea and tears: a review and personal observations. CLAO F 1988; 14: 23-32.

44 Bates AK, Morris RJ, Stapleton F, Minassian DC, Dart JKG. 'Sterile' corneal infiltrates in contact lens wearers. Eye 1989; 3: 803-10.
45 Stein RM, Clinch TE, Cohen EJ, Genvert GI, Arentsen JJ, Laibson PR. Infected vs sterile corneal infiltrates in contact lens wearers. Am $\mathcal{f}$ Ophthalmo 1988; 105: 632-6.

46 Stern GA. Corneal infections in contact lens wearers. Int Ophthalmol Clin 1991 31: $147-61$

47 Zadnik K, Mutti D. Inferior arcuate corneal staining in soft contact lens wearers. Int Contact Lens Clin 1983; 12: 110-5.

48 Dixon J, Lawazek E. Corneal vascularisation due to contact lenses. Arch Ophthalmol 1963; 69: 72-5.

49 Mobilia EF, Kenyon KR. Contact lens-induced corneal warpage. Int Ophthalmol Clin 1986; 26: 43-53.

50 Wilhelmus KR. Review of clinical experience with microbial keratitis associated with contact lenses. $C L A O \mathcal{O} 1987 ; 13: 211-4$.

51 Alfonso E, Mandelbaum S, Fox MJ, Forster RK. Ulcerative keratitis associated with contact lens wear. Am $\mathcal{f}$ Ophthalmol 1986; 101: 429-33.

52 Galentine PG, Cohen EJ, Laibson PR, Adams CP, Michaud R, Arentsen JJ Corneal ulcers associated with contact lens wear. Arch Ophthalmol 1984; 102 $891-4$

53 Schein OD, Glynn RJ, Poggio EC, Seddon JH, Kenyon KR. The relative risk of ulcerative keratitis among users of daily-wear and extended-wear sof contact lenses. A case control study. $N$ Engl f Med 1989; 321: 773-8.

54 Dart JKG, Stapleton F, Minassian D. Contact lenses and other risk factors in microbial keratitis. Lancet 1991; 338: 650-3.

55 Poggio EC, Glynn RJ, Schein OD, Seddon JM, Shannon MJ, Scardino VA, et al. The incidence of ulcerative keratitis among users of daily-wear and extended-wear soft contact lenses. N Engl f Med 1989; 321: 779-83.

56 Weissman BA, Remba MJ, Fugedy E. Results of the extended wear contact lens survey of the contact lens section of the American Optometric Association. F Am Optom Ass 1987; 58: 166-71.

57 Moore MB, McCulley JP, Luckenbach M, Gelender H, Newton C, McDonald $\mathrm{MB}$, et al. Acanthamoeba keratitis associated with soft contact lenses. MB, et al. Acanthamoeba keratitis

58 Mannis MJ, Tamaru R, Roth AM, Burns M, Thurkill C. Acanthamoeba sclerokeratitis. Determining diagnostic criteria. Arch Ophthalmol 1986; 104 1313-7.

59 Johns KJ, O'Day DM, Feman SS. Chorioretinitis in the contralateral eye of a patient with Acanthamoeba keratitis. Ophthalmology 1988; 95: 635-9.

60 Stehr-Green JK, Bailey TM, Visvesvara GS. The epidemiology of Acanthamoeb keratitis in the United States. Am F Ophthalmol 1989; 107: 331-6.

61 Bacon ASB, Matthews TD, Dart JKG. Acanthamoeba keratitis in wearers of disposable contact lenses. [Abstract] Oxford Ophthalmological Congress, 1992.

62 Stehr-Green JK, Bailey TM, Brandt FH, Carr JH, Bond WW, Visvesvara GS. Acanthamoeba keratitis in soft contact lens wearers: a case control study. FAMA 1987; 258: $57-60$.

63 Ficker L. Acanthamoeba keratitis - the quest for a better prognosis. Eye 1988; 2 (Suppl): $537-45$.

64 Larkin DFP, Kilvington S, Dart JKG. Treatment of Acanthamoeba keratitis with topical polyhexamethylene biguanide. Ophthalmology 1992; 99: 185-91.

65 Auran JD, Starr MB, Jakobiec FA. Acanthamoeba keratitis. A review of the literature. Cormea 1987; 6: 2-26.

66 Lindquist TD, Sher NA, Doughman DJ. Clinical signs and medical therapy of early Acanthamoeba keratitis. Arch Ophthalmol 1988; 106: 1202-6.

67 Moore MB, McCulley JP, Kaufman HE, Robin JB. Radial keratoneuritis as a presenting sign in Acanthamoeba keratitis. Ophthalmology 1986; 93: 1310-5.

68 Theodore FH, Jakobiec FA, Jueghter KB, Ma P, Troutman RC, Pang PM et al. The diagnostic value of a ring infiltrate in Acanthamoebic keratitis. Ophthalmology 1985; 92: 1471-9.

69 Hamano H, Kitano J, Mitsunaga S, Kojima S, Kissling GE. Adverse effects of contact lens wear in a large Japanese population. $C L A O \mathcal{F} 1985 ; 11: 141-7$.

70 Binder PS. Myopic extended wear with the Hydrocurve II soft contact lens. Ophthalmology 1983:90:623-6.

71 Stark WJ, Martin NF. Extended wear contact lenses for myopic correction. Arch Ophthalmol 1981; 99: 1963-6.

72 Cuhna M, Thomassen T, Cohen E, Genvert G, Arentsen J, Laibson P. Complications associated with soft lens use. $C L A O \mathcal{F} 1987 ; 13: 107-11$.

73 Driebe WT. Disposable soft contact lenses. Surv Ophthalmol 1989; 34: +1-6.

4 John T. How safe are disposable contact lenses? Am $\mathcal{F}$ Ophthalmol 1991; 111 : 766-8.

75 Josephson JE, Caffery BE, Campbell I, Slomovic AR. Disposable contact lenses vs contact lens maintenance for extended wear. $C L A O \mathcal{F} 1990 ; 16$ : $184-8$.

76 Gruber $\mathrm{E}$. The disposable contact lens: a new concept in extended wear. $C L A O$ F 1988; 14: 195-8.

77 Donshik P, Weinstock FJ, Weschler S, Asbell P, Atwood J, Davis H, et al. Disposable hydrogel contact lenses for extended wear. CLAO F 1988; 14 : 191-4.

78 Mathews TD, Frazer DG, Minassian DC, Radford CF, Dart JKG. Risks of keratitis and patterns of use with disposable contact lenses. Arch Ophthalmol 1992 , in press.

79 Buehler PO, Schein OD, Stamler JF, Verdier DD, Katz J. The increased risk of ulcerative keratitis among disposable soft contact lens users. Arch Ophthalmol 1992, in press.

80 Maguen E, Tsai JC, Martinez M, Rosner I, Caroline P, Macy JI, et al. A retrospective study of disposable lens wear in 100 patients. Ophthalmologv 1991; 98: 1685-9.

81 Smith RE, MacRae SM. Contact lenses - convenience and complications. NEnglf Med 1989; 321: 824-6. 